\title{
Evaluation of Helicobacter Pylori eradication in pediatric patients by triple therapy plus lactoferrin and probiotics compared to triple therapy alone
}

Salvatore Tolone ${ }^{1}$, Valeria Pellino ${ }^{2}$, Giovanna Vitaliti ${ }^{3}$, Angela lanzafame ${ }^{3}$ and Carlo Tolone ${ }^{2^{*}}$

\begin{abstract}
Background: To evaluate whether the addition of a probiotic could improve Helicobacter pylori (H.P.) eradication rates and reduce the side effects of treatment in children.

Methods: Between July 2008 and July 2011 all patients with a clinical, laboratory and endoscopic diagnosis of H.P. positive gastritis referred to our Unit were included in the study. Patients suffering from allergy to any of drugs used in the study, with previous attempts to eradicate H.P. and those who received antibiotics, PPIs or probiotics within 4 weeks were excluded from the present study. Patients were randomized into two therapy regimens (group A and B): both groups received standard triple treatment (omeprazole, amoxicillin and clarithromycin) while only group B patients were also given a probiotic (Probinul - Cadigroup). Patients compliance was evaluated at the end of the treatment. Successful eradication was defined as a negative 13 C-urea breath test (C13-ubt) result four weeks after therapy discontinuation.

Results: A total of 68 histopathologically proven H.P.-infection children (32 male and 36 females) were included in the study. All of the patients in both groups used more than $90 \%$ of the therapies and no patients were lost at follow up. All side effects were selflimiting and disappeared once the therapy was terminated. Epigastric pain was observed in 6 (17.6\%) group A vs $2(5.8 \%)$ group B patients ( $P<0.05)$, nausea in $3(8.8 \%)$ group A vs 1 (2.9\%) group B patients $(P<0.05)$; vomiting and diarrhea were observed in 2(5.8\%) and 8 (23.5\%) group A patients, respectively and never in group $B(P<0.05)$. There was no significant difference between the two groups in terms of constipation (5.8\% in group A and B). Four weeks after the completion of therapy, 56/68 patients (82.3\%) tested negative for H.P. on C13-ubt. H.P. was eradicated in 26 patients (76.4\%) in group A and in 30 patients (88.2\%) in group B. There was no significantly difference in the rate of H.P. eradication between group $A$ and group $B(p=0.1)$, although the success rate for H.P. eradication was higher in group $B$ than in group $A$.
\end{abstract}

Conclusion: The addition of a probiotic formula to triple therapy significantly decreased the frequency of epigastric pain, nausea, vomiting and diarrhea.

Keywords: H.P, H.P. eradication, Children gastritis, Probiotic

\footnotetext{
* Correspondence: carlo.tolone@libero.it

${ }^{2}$ Department of Pediatrics, Second University of Naples, Via L De Crecchio,

Naples 80138, Italy

Full list of author information is available at the end of the article
} 


\section{Background}

Helicobacter pylori (H.P.) infection is a major cause of chronic gastritis and peptic ulcers and it is a risk factor for gastric malignancies, adenocarcinoma and low grade gastric mucosa associated lymphoid tissue (MALT) lymphoma [1]. According to the Maastricht III consensus report, H.P. eradication is recommended for patients with gastroduodenal ulcer disease, atrophic gastritis, MALT lymphoma, first degree relatives of patients with gastric cancer, patients with unexplained iron deficiency anemia and chronic idiopathic thrombocytopenic purpura.

In both developed and developing countries, H.P. infection is most frequently acquired during childhood, and it is associated with family size, familial clustering, low socioeconomic status and education. The first line treatment for H.P. infection, as recommended by the Maastricht 2-2000 Consensus Report, is a 7-14 days triple therapy which includes amoxicilline, clarithromycin, OR metronidazole and a proton-pump inhibitor (PPI) [2], though new strategies may be required for treatment both in adults and children. As for adults, "infanti" treatment will fail in approximately $10-35 \%$ of patients, and H.P. infection will remain resulting from several factors, including nonadherence to therapy related to adverse effects or complicated dosing regimens and increasing antibiotic resistance [3-5]. To overcome this problem, both in adults than in children, alternative and adjuvant therapies have been added to conventional treatment, such as probiotics (PB) [6,7]. Although there is some controversy as to whether supplementation with probiotic improves the H.P. eradication rates [8-10], several meta-analysis and reviews have suggested that probiotics can improve the H.P. eradication rate by approximately $5-10 \%$ [10-13]. However, it is evident that not all probiotics are created equal, that the beneficial effects are strain specific, and each strain must be evaluated individually. Besides treatment studies on children are limited by the small number of infected children in each individual center [14-16], therefore this study aimed to evaluate whether the addition of a commercially multi-strain probiotics to a 7 days triple therapy in children could improve H.P. eradication rates and reduce the side effects of treatment.

\section{Methods}

Between July 2008 and July 2011 children referred to the Department of Pediatrics of the University of Naples with dyspeptic complaints such as heartburn, dyspepsia, nausea and epigastric pain, were enrolled in this study. The study was approved by Ethical Committee of the University of Naples.

Pediatric patients with a clinical, laboratory and endoscopic diagnosis of H.P. positive gastritis and the other conditions necessary H.P. eradication for Maastricht III consensus report were included in the study. Exclusion criteria were: 1) allergy to any of drugs used in the study 2) previous attempts to eradicate H.P. 3) receipt of antibiotics, PPIs or probiotics within 4 weeks of the study. Informed consent was obtained from all patients and all positive $13 \mathrm{C}$-urea breath test (C13-ubt) patients underwent upper endoscopy.

Two samples were taken from the gastric antrum and compass for histologic assessment, and the biopsy specimens were fixed in 10\% formalin solution. Preparation were stained with hematoxylin-eosin and modified Giemsa stains and were evaluated according to updated Sydney classification.

H.P. positive patients were randomized into two therapy regimens: patients in group A were given omeprazole (1 mg/kg before breakfast), amoxicillin $(50 \mathrm{mg} / \mathrm{kg}$ b.i.d. after meals), clarithromycin (15 mg/kg b.i.d. after meals) for 7 days, whereas patients in group B were given the same drugs and a probiotic once a day for 7 days.

Patients were instructed to take PPI 30 mins before breakfast, the antibiotics 5 mins after breakfast and dinner, and PB supplement in the afternoon. The PB supplement was taken in a commercially available form containing $5 \times$ 109 Lactobacillus plantarum, $2 \times 109$ L. reuterii, $2 \times 109 \mathrm{~L}$. casei subsp. rhamnosus, $2 \times 109$ Bifidobacterium infantis and B. longum, $1 \times 109$ L. salivarius, $1 \times 109$ L. acidophilus, $5 \times 109$ Streptococcus termophilus, and $1 \times 109 \mathrm{~L}$. sporogenes (Lactobacillaceae). This PB formula ( $5 \mathrm{~g} /$ dayose q.d.) (Probinul - Cadigroup) was selected because it contains high concentrations of a wide range of bacteria, as well as inuline as a prebiotic.

Parents were asked to report any side effects of therapy during the treatment period and were given a possible side effect list, such as epigastric pain, nausea, diarrhea and constipation. Patients compliance was evaluated at the end of the treatment on the basis of diary that patients were asked to fill with pill count and was considered as completed if $>90 \%$ of the medication had been taken.

Successful eradication was defined as a negative C13ubt result four weeks after discontinuation of the therapy.

\section{Statistical analysis}

Data were collected prospectically in an electronic database (Excell Microsoft). Fisher's exact test was carried out to determine the efficacy of the two treatments. Results were considered statistically significant for $\mathrm{P}$ values less than 0.05 .

\section{Results}

A total of 68 histopathologically proven H.P.-infection children (32 male and 36 females) were included in the study. The mean age of all children was $8,3+/-3,4$ years.

The patients were randomized into group A (triple therapy n 34 patients) and group B (triple therapy plus probiotic n 34 patients) for H.P. eradication. The age 
Table 1 Incidence of side effects of the treatment

\begin{tabular}{lccc}
\hline Side Effects & Group A $(\mathbf{N}=\mathbf{3 4})$ & Group B $(\mathbf{N}=\mathbf{3 4})$ & P value \\
\hline Epigastric pain & $6(17.6 \%)$ & $2(5.8 \%)$ & $<0.05$ \\
Nausea & $3(8.8 \%)$ & $1(2.9 \%)$ & $<0.05$ \\
Vomiting & $2(5.8 \%)$ & 0 & $<0.05$ \\
Diarrhea & $8(23.5 \%)$ & 0 & $<0.05$ \\
Constipation & $2(5.8 \%)$ & $2(5.8 \%)$ & N.S. \\
\hline
\end{tabular}

distribution of patients and gender in group A and group B were similar.

All of parents returned the daily diary filled up with side-effects and pill count.

All of the patients in both groups used more than $90 \%$ of the therapies and no patients were lost at follow up. The prevalence of epigastric pain, nausea, vomiting and diarrhea was significantly higher $(\mathrm{P}<0.05)$ in group $\mathrm{A}$ than in group $B$. There was no significant difference between the two groups in terms of constipation. (Detailed data on side effects are summarized in Table 1).

All side effects were self-limiting and disappeared once the therapy was terminated.

Four weeks after the completion of therapy, 56/68 patients $(82.3 \%)$ tested negative for H.P. on C13-ubt. H. P. was eradicated in 26 patients $(76.4 \%)$ in group A and in 30 patients $(88.2 \%)$ in group B (Figure 1 ). There was no significantly difference in the rate of H.P. eradication between group A and group B $(p=0,1)$, although the success rate for H.P. eradication was higher in group $B$ than in group $\mathrm{A}$.

\section{Discussion}

It is well known that childhood is an important period for acquisition of H.P. infection. Intrafamiliar trasmission of the infection, especially from mother to child, has been hypothisized as the major mode of dissemination [17]. H.P. is considered to be the major cause of chronic gastritis and duodenal ulcer in childhood and an important cofactor in the development of gastric cancer
[18]. Unfortunately eradication therapy is not always successful and reports of failed H.P. eradication therapy are increasing. Therefore, recent review studies report eradication rates of standard triple therapy in children below 75\% [14,19]. Moreover this regimens have the disadvantage of risking poor compliance and causing sideeffects especially in children. Nowadays there is considerable interest in alternative therapies or adjunctive treatment against H.P. to reduce some of the drawbacks associated with the antibiotic consumption and to increase the eradication rates. Some adjuvant therapy trials both in adults and in children incorporate probiotics [20-22].

In our study H.P. eradication was achieved in $82.3 \%$ of patients. A little increase in the eradication rate and a significant reduction in side effects were observed in the group treated with triple therapy plus Probinul PB. Resistant patients were offered to second line therapy (omeprazole $1 \mathrm{mg} / \mathrm{kg} / \mathrm{d}$, amoxicillin $50 \mathrm{mg} / \mathrm{kg} / \mathrm{d}$ and metronidazole $20 \mathrm{mg} / \mathrm{kg} / \mathrm{d}$ ), according to NASPGHAN guidelines, confirming the contribution of a high background resistance to clarithromycin. Also, guidelines on HP infection in children issued so far suggest that the antibiotic susceptibility test should be performed whenever available [15]. However, we did not performed susceptibility test for first line antibiotic therapy.

Probiotics include viable microorganism that have a beneficial effects for the prevention and treatment of specific pathological conditions [23]. Principle mechanisms include interference with pathogenic toxins, preservation of cellular physiology, interference with pathogen attachment and interaction with normal microbiota $[24,25]$.

In addition, stimulation or modulation of immune responses, both within the lumen and systemically, although not clearly linked to H.P. infection, may contribute $[26,27]$. Besides probiotics may be beneficial in reducing adverse effects and increasing tolerability of HP eradication regimens. Several studies evaluated whether probiotic supplementation might help to prevent or reduce drug-

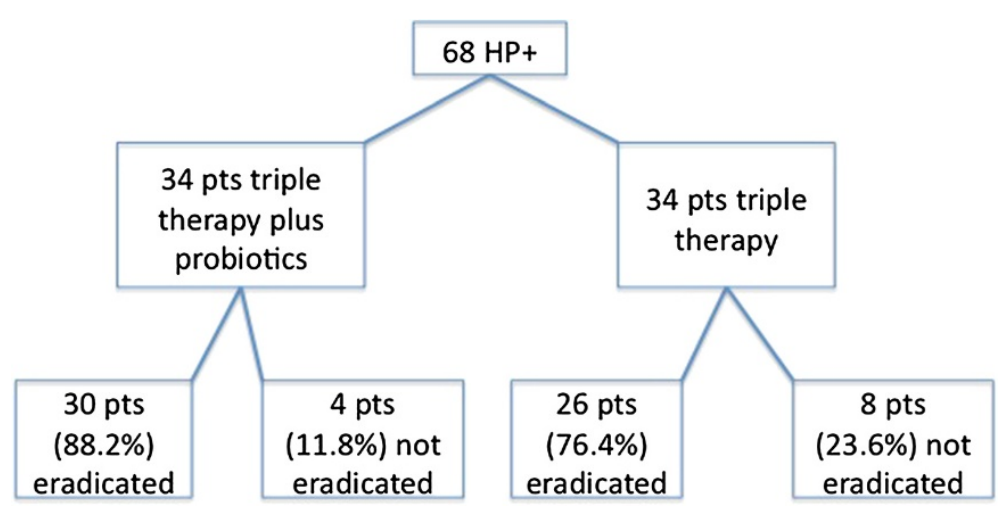

Figure 1 Patients enrollment and therapy flowchart. 
related side effects during H.P. eradication therapy in adults [28-30]. Up to date, in the pediatric population, few randomized studies have evaluated whether consumption of probiotics could increase H.P. eradication rates and reduce the side effects of treatment [31-33]. In fact, in a recent trial by Szajewska et al. [33] was identified that the use of Lactobacillus GG along with standard triple therapy didn't resulted in an increased eradication rate and decreased overall therapy-related side effects.

Some of these trials do not provide evidence on the beneficial effect in children of supplementation of probiotics to triple therapy for eradicating H.P. infection nor for positively affecting therapy related symptoms and overall treatment tolerance [34].

However other investigators have shown that in symptomatic H.P. positive children, the occurrence of antibiotic associated side-effects was significantly reduced by the addition of probiotics compared with the placebo supplemented group [31].

H.P. eradication depends on a number of factor, including patients compliance, adverse effects, bacterial resistance, poor drug distribution and concentration, socioeconomic conditions and geographic differences. So antibiotic related side effects may be depending on different probiotic strains taken during the H.P. eradication therapy.

In our study the choice of the Probinul probiotic formula was determinated by the fact that it contains high concentration of a wide range of bacteria, as well as inuline as prebiotic. Previously we have demonstrated that this probiotic formula was able to reduce antibiotic gastro-intestinal related side effects in children treated with amoxicillin therapy for pneumonia infections [35].

Besides De Bortoli et al. have demonstrated that the addition of bovine lactoferrin and this probiotic formula to standard triple eradication therapy could improve the H.P. eradication rate and reduce side effects in adult [36].

In this study the combination of standard triple therapy + probiotic + bovine lactoferrin was more effective than triple therapy alone. This could be explained by the combined effect of the bactericidal and bacteriostatic properties of bovine lactoferrin and the mechanism of the probiotics including their direct, nonspecific, bacteriostatic activity and their enhancement of immunoglobulin A production [37].

Probiotics may act through both immunological as well as non-immunological mechanism in H.P. eradication. The latest mechanism includes providing antimicrobial substances, competing with H.P. for adhesion and providing a mucosal barrier. When there are decreases in side effects, compliance improves [26]. The efficacy of probiotic supplementation for reducing side effects during the course of anti HP regimens appears to be dependent of which probiotic species are used. In fact probiotics must be metabolically active in the intestinal lumen, where they should survive but not persist after the therapy regimen has been completed. They must be acid and bile resistant and should be antagonist to pathogenic bacteria [38-40].

The present study has shown that the addiction of the Probinul probiotic formula to standard antibiotic treatment reduced in children H.P. therapy-associated side effects (occurrence of side effects: $61.5 \%$ in group A vs $14.5 \%$ in group B). The H.P. eradication was achieved in 26 of 34 patients in group A (76.4\%) and in 30 of 34 patients $(88.2 \%)$ in group B. Although the success rate was higher in group A than in group B, the different was not significant. Also, we preferred to use the conventional 7-days triple therapy to better highlight the efficacy of probiotic supplement; furthermore extending the duration of therapy form 7 to 14 days is not clearly associated with an increased eradication rate [41]. However, our study presents some limitations, as a relative small number of patients and absence of a placebo-control group for the probiotics; also, the treatment group with probiotics is likely to be superior to the control group if the sample size is larger.

In conclusion our study suggests that the addition of this probiotic formula to triple therapy did not increase (significantly) the H.P. eradication rates; however it significantly decreased the frequency of epigastric pain, nausea, vomiting and diarrhea.

In children with H.P. infection, we think, there is evidence to recommend the use of this probiotic formula along with standard triple therapy as an option for decreasing overall therapy related side effects and slightly increasing the eradication rates.

\section{Competing interests}

The authors declare that they have no competing interests.

\section{Authors' contributions}

TS designed the study and wrote the manuscript; PV, VG and LA provided data collection and were involved in editing the manuscript; TC designed the study, wrote the manuscript and gave final approval of the version to be published. All authors read and approved the final manuscript.

\section{Author details}

'Division of General and Bariatric Surgery, Second University of Naples, Via Pansini 5, Naples 80131, Italy. ${ }^{2}$ Department of Pediatrics, Second University of Naples, Via L De Crecchio, Naples 80138, Italy. ${ }^{3}$ Department of Medical and Pediatrics Science, Via SSofia n.78, Catania 95123, Italy.

Received: 14 July 2012 Accepted: 17 October 2012

Published: 31 October 2012

References

1. Suerbaum S, Michetti P: Helicobacter pylori infection. N Engl J Med 2002, 347:1175-1186.

2. Malfertheiner $P$, Mégraud F, O'Morain C, Hungin AP, Jones R, Axon A, Graham DY, Tytgat G, European Helicobacter Pylori Study Group (EHPSG): Current concepts in the management of Helicobacter pylori infectionthe Maastricht 2-2000 Consensus Report. Aliment Pharmacol Ther 2002, 16:167-180 
3. Chey WD, Wong BC, Practice Parameters Committee of the American College of Gastroenterology: American College of Gastroenterology guideline on the management of Helicobacter pylori infection. Am J Gastroenterol 2007, 102:1808-1825.

4. Malfertheiner P, Megraud F, O'Morain C, Bazzoli F, El-Omar E, Graham D, Hunt R, Rokkas T, Vakil N, Kuipers EJ: Current concepts in the management of Helicobacter pylori infection: the Maastricht III Consensus Report. Gut 2007, 56:772-781.

5. Mamori S, Higashida A, Kawara F, Ohnishi K, Takeda A, Senda E, Ashida C, Yamada $\mathrm{H}$ : Age-dependent eradication of Helicobacter pylori in Japanese patients. World J Gastroenterol 2010, 16:4176-4179.

6. Gotteland M, Brunser $\mathrm{O}$, Cruchet S: Systematic review: are probiotics useful in controlling gastric colonization by Helicobacter pylori? Aliment Pharmacol Ther 2006, 23:1077-1086.

7. Tong JL, Ran ZH, Shen J, Zhang CX, Xiao SD: Meta-analysis: the effect of supplementation with probiotics on eradication rates and adverse events during Helicobacter pylori eradication therapy. Aliment Pharmacol Ther 2007, 25:155-168.

8. Ozdil K, Calhan T, Sahin A, Senates E, Kahraman R, Yǘzbasioglu B, Demirdag H, Demirsoy H, Sökmen MH: Levofloxacin based sequential and triple therapy compared with standard plus probiotic combination for Helicobacter pylori eradication. Hepatogastroenterology 2011, 58:1148-1152.

9. Tursi A, Brandimarte G, Giorgetti GM, Modeo ME: Effect of Lactobacillus casei supplementation on the effectiveness and tolerability of a new second-line 10-day quadruple therapy after failure of a first attempt to cure Helicobacter pylori infection. Med Sci Monit 2004, 10:CR662-CR666.

10. Medeiros JA, Gonçalves TM, Boyanova L, Pereira MI, de Carvalho JN, Pereira AM, Cabrita AM: Evaluation of Helicobacter pylori eradication by triple therapy plus Lactobacillus acidophilus compared to triple therapy alone. Eur J Clin Microbiol Infect Dis 2011, 30:555-559.

11. Szajewska H, Horvath A, Piwowarczyk A: Meta-analysis: the effects of Saccharomyces boulardii supplementation on Helicobacter pylori eradication rates and side effects during treatment. Aliment Pharmacol Ther 2010, 32:1069-1079.

12. Chenoll E, Casinos B, Bataller E, Astals P, Echevarría J, Iglesias JR, Balbarie P, Ramón D, Genovés S: Novel probiotic Bifidobacterium bifidum CECT 7366 strain active against the pathogenic bacterium Helicobacter pylori. Appl Environ Microbiol 2011, 77:1335-1343.

13. Wilhelm SM, Johnson JL, Kale-Pradhan PB: Treating bugs with bugs: the role of probiotics as adjunctive therapy for Helicobacter pylori. Ann Pharmacother 2011, 45:960-966.

14. Francavilla R, Lionetti E, Castellaneta SP, Magistà AM, Boscarelli G, Piscitelli D, Amoruso A, Di Leo A, Miniello VL, Francavilla A, et al: Improved efficacy of 10-Day sequential treatment for Helicobacter pylori eradication in children: a randomized trial. Gastroenterology 2005, 129:1414-1419.

15. Oderda G, Shcherbakov P, Bontems P, Urruzuno P, Romano C, Gottrand F, Gómez MJ, Ravelli A, Gandullia P, Roma E, European Pediatric Task Force on Helicobacter pylori, et al: Results from the pediatric European register for treatment of Helicobacter pylori (PERTH). Helicobacter 2007, 12:150-156.

16. Lionetti E, Indrio F, Pavone L, Borrelli G, Cavallo L, Francavilla R: Role of probiotics in pediatric patients with Helicobacter pylori infection: a comprehensive review of the literature. Helicobacter 2010, 15:79-87.

17. Kivi M, Tindberg Y, Sörberg M, Casswall TH, Befrits R, Hellström PM, Bengtsson C, Engstrand L, Granström M: Concordance of Helicobacter pylori strains within families. J Clin Microbiol 2003, 41:5604-5608.

18. Uemura N, Okamoto S, Yamamoto S, Matsumura N, Yamaguchi S, Yamakido M, Taniyama K, Sasaki N, Schlemper RJ: Helicobacter pylori infection and the development of gastric cancer. N Engl J Med 2001, 345:784-789.

19. Kato S, Konno M, Maisawa S, Tajiri H, Yoshimura N, Shimizu T, Toyoda S, Nakayama $Y$, linuma $K$ : Results of triple eradication therapy in Japanese children: a retrospective multicenter study. J Gastroenterol 2004, 39:838-843.

20. Song MJ, Park DI, Park JH, Kim HJ, Cho YK, Sohn Cl, Jeon WK, Kim BI: The effect of probiotics and mucoprotective agents on PPI-based triple therapy for eradication of Helicobacter pylori. Helicobacter 2010, 15:206-213.

21. Kim MN, Kim N, Lee SH, Park YS, Hwang JH, Kim JW, Jeong SH, Lee DH, Kim JS, Jung HC, Song IS: The effects of probiotics on PPI-triple therapy for Helicobacter pylori eradication. Helicobacter 2008, 13:261-268.

22. Chiesa C, Pacifico L, Anania C, Poggiogalle E, Chiarelli F, Osborn JF: Helicobacter pylori therapy in children: overview and challenges. Int J Immunopathol Pharmacol 2010, 23:405-416.
23. Jonkers $D$, Stockbrügger R: Review article: Probiotics in gastrointestinal and liver diseases. Aliment Pharmacol Ther 2007, 26:133-148.

24. Leonardi S, Miraglia del Giudice M, La Rosa M, Bellanti J: Atopic disease, immune and environment. Allergy Asthma Proc 2007, 28:410-417.

25. del Giudice MM, Rocco A, Capristo C: Probiotics in the atopic march: highlights and new insights. Dig Liv Dis 2006, 38:S288-S290.

26. McFarland LV: Systematic review and meta-analysis of Saccharomyces boulardii in adult patients. World J Gastroenterol 2010, 16:2202-2222.

27. Franceschi F, Cazzato A, Nista EC, Scarpellini E, Roccarina D, Gigante G, Gasbarrini G, Gasbarrini A: Role of probiotics in patients with Helicobacter pylori infection. Helicobacter 2007, 12:59-63.

28. Armuzzi A, Cremonini F, Bartolozzi F, Canducci F, Candelli M, Ojetti V, Cammarota G, Anti M, De Lorenzo A, Pola P, et al: The effect of oral administration of Lactobacillus GG on antibiotic-associated gastrointestinal side-effects during Helicobacter pylori eradication therapy. Aliment Pharmacol Ther 2001, 15:163-169.

29. Cremonini F, Di Caro S, Covino M, Armuzzi A, Gabrielli M, Santarelli L, Nista EC, Cammarota G, Gasbarrini G, Gasbarrini A: Effect of different probiotic preparations on anti-helicobacter pylori therapy-related side effects: a parallel group, triple blind, placebo-controlled study. Am J Gastroenterol 2002, 97:2744-2749.

30. Myllyluoma E, Veijola L, Ahlroos T, Tynkkynen S, Kankuri E, Vapaatalo H, Rautelin $\mathrm{H}$, Korpela R: Probiotic supplementation improves tolerance to Helicobacter pylori eradication therapy-a placebo-controlled, doubleblind randomized pilot study. Aliment Pharmacol Ther 2005, 21:1263-1272.

31. Lionetti E, Miniello VL, Castellaneta SP, Magistá AM, de Canio A, Maurogiovanni G, lerardi E, Cavallo L, Francavilla R: Lactobacillus reuteri therapy to reduce side-effects during anti-Helicobacter pylori treatment in children: a randomized placebo controlled trial. Aliment Pharmacol Ther 2006, 24:1461-1468

32. Hurduc V, Plesca D, Dragomir D, Sajin M, Vandenplas Y: A randomized, open trial evaluating the effect of Saccharomyces boulardii on the eradication rate of Helicobacter pylori infection in children. Acta Paediatr 2009, 98:127-131.

33. Szajewska H, Albrecht P, Topczewska-Cabanek A: Randomized, doubleblind, placebo-controlled trial: effect of lactobacillus GG supplementation on Helicobacter pylori eradication rates and side effects during treatment in children. J Pediatr Gastroenterol Nutr 2009, 48:431-436

34. Goldman CG, Barrado DA, Balcarce N, Rua EC, Oshiro M, Calcagno ML, Janjetic M, Fuda J, Weill R, Salgueiro MJ, et al: Effect of a probiotic food as an adjuvant to triple therapy for eradication of Helicobacter pylori infection in children. Nutrition 2006, 22:984-988.

35. Tolone C: Efficacy of Probinul in reduction of antibiotic gastro-intestinal related side effects in children with respiratory infections. In Proceeding of $62^{\circ}$ National Congress of Italian Society of Pediatrics; 2006.

36. de Bortoli N, Leonardi G, Ciancia E, Merlo A, Bellini M, Costa F, Mumolo MG, Ricchiuti A, Cristiani F, Santi S, et al: Helicobacter pylori eradication: a randomized prospective study of triple therapy versus triple therapy plus lactoferrin and probiotics. Am J Gastroenterol 2007, 102:951-956.

37. Fukushima Y, Kawata Y, Hara H, Terada A, Mitsuoka T: Effect of a probiotic formula on intestinal immunoglobulin A production in healthy children Int J Food Microbiol 1998, 42:39-44.

38. Smythies LE, Waites KB, Lindsey JR, Harris PR, Ghiara P, Smith PD: Helicobacter pylori-induced mucosal inflammation is Th1 mediated and exacerbated in IL-4, but not IFN-gamma, gene-deficient mice. J Immunol 2000, 165:1022-1029.

39. del Giudice M, De Luca MG: The role of probiotics in the clinical management of food allergy and atopic dermatitis. J Clin Gastroenterol 2004, 38(6 Suppl):S84-S85.

40. Del Giudice MM, Leonardi S, Maiello N, Brunese FP: Food allergy and probiotics in childhood. J Clin Gastroenterol 2010, 44:S22-S25.

41. Hsu PI, Wu DC, Wu JY, Graham DY: Is there a benefit extending the duration of Helicobacter Pylori sequential therapy to 14 days? Helicobacter 2011, 16:146-152.

\section{doi:10.1186/1824-7288-38-63}

Cite this article as: Tolone et al:: Evaluation of Helicobacter Pylori eradication in pediatric patients by triple therapy plus lactoferrin and probiotics compared to triple therapy alone. Italian Journal of Pediatrics $201238: 63$. 